\title{
Adição de microssílica e a secagem de concretos refratários
}

\section{(Microsilica addition and the drying of refractory castables)}

\author{
R. D. dos Anjos, M. R. Ismael, F. T. Ramal Jr, V. C. Pandolfelli \\ Departamento de Engenharia de Materiais - DEMa \\ Universidade Federal de S. Carlos - UFSCar \\ Rod. Washington Luiz, km 235, C.P. 676, S. Carlos, SP 13565-905 \\ renataanjos@polvo.ufscar.br,vicpando@power.ufscar.br
}

\begin{abstract}
Resumo
A microssílica é o material superfino $(<1 \mu \mathrm{m})$ mais amplamente utilizado em concretos refratários, pois melhora significativamente seu empacotamento durante a moldagem, sua fluidez e resistência mecânica a verde. Em elevadas temperaturas também são observadas diversas vantagens, tais como aumento na resistência à corrosão e resistência ao choque térmico, características advindas principalmente da fase mulita, que se forma devido à reação entre alumina e microssílica nas condições de trabalho. Entretanto, estudos referentes ao efeito da adição desse material na etapa de secagem, especificamente no comportamento de explosão, ainda são escassos na literatura. Neste contexto, este trabalho teve como objetivo principal relacionar o teor de microssílica e a variação da temperatura de cura com algumas propriedades dos concretos refratários. Os resultados mostraram que houve aumento da resistência mecânica e redução de permeabilidade com a elevação do teor de microssílica incorporada ao concreto, modificando conseqüentemente o comportamento de explosão. Além disso, tais variáveis também sofreram significativa influência da temperatura utilizada na cura dos concretos.
\end{abstract}

Palavras-chave: concretos refratários, microssílica, temperatura de cura.

\begin{abstract}
Microsilica is the most used superfine material $(<1 \mu \mathrm{m})$ in the refractory castables, because it improves its flow, packing density and green mechanical strength. At high temperatures many other advantages are observed, such as the superior corrosion and thermal shock resistances, due to the mullite phase formed by the reaction between alumina and microsilica in the working conditions. Nevertheless, papers relating to the effect of microsílica addition during drying stage are scarce, specifically concerning the explosion behavior. Therefore, the purpose of this work was to establish the relationship between microsilica content and curing temperature variation with some refractory castables' properties. The results showed that higher contents of microsilica on the refractory castables composition promote higher mechanical strength and a reduction of permeability, modifying the castable explosion behavior. The properties evaluated were also effected by the curing temperature applied.
\end{abstract}

Keywords: refractory castables, microsilica, curing temperature.

\section{INTRODUÇÃO}

A microssílica é um subproduto da reação entre quartzo de alta pureza e carvão na produção de silício metálico e ligas ferro-silício. Também é obtida na produção de outras ligas, tais como ferrocromo e ferro-manganês. A microssílica é constituída por finas partículas amorfas e esféricas de dióxido de silício, com diâmetro médio de $0,1 \mu \mathrm{m}$ e com área superficial próxima a 20 m²/g [1].

Quando adicionada à formulação do concreto, a microssílica é usada para preencher parte dos vazios disponíveis na distribuição granulométrica, resultando em uma menor quantidade de água para obtenção de uma determinada fluidez [2]. Além disso, o contato desse material com a água e o cimento disponível no concreto origina uma reação conhecida na literatura como pozolânica. Tal reação tem como principal característica a formação de um gel que se distribui por toda estrutura do material, elevando assim a resistência mecânica a verde do concreto [3].
Além dessas vantagens, a microssílica propicia a formação de mulita em concretos aluminosos quando em uso em elevadas temperaturas, conferindo maior resistência mecânica a quente, elevada resistência à abrasão e ao choque térmico [1].

Ao mesmo tempo em que eleva a resistência mecânica, a adição de microssílica também pode reduzir a permeabilidade do material (aumento do empacotamento e formação de gel). Tendo em vista que o comportamento de explosão é dependente de um balanço entre essas duas propriedades, pode-se afirmar que tal adição poderia favorecer a resistência à explosão através do aumento da resistência mecânica. No entanto, poderia dificultar a eliminação da água, ocasionando pressurização e a possível explosão do refratário, através da redução na permeabilidade. Desta forma, seria importante estabelecer qual a relevância dessas variáveis no comportamento de explosão de concretos contendo microssílica.

Estudos específicos sobre a microssílica e sua influência na etapa de secagem, particularmente no comportamento de 
explosão, ainda são escassos na literatura. Deste modo, o presente trabalho teve como finalidade relacionar o teor de microssílica com a permeabilidade, resistência mecânica e resistência à explosão de concretos refratários de ultrabaixo teor de cimento. Adicionalmente, também se verificou a relação de dependência dessas propriedades com a temperatura utilizada para a cura dos concretos.

\section{MATERIAIS E MÉTODOS}

\section{Formulação e mistura}

O estudo foi realizado utilizando-se concretos refratários de alta alumina com ultrabaixo teor de cimento. As principais matérias-primas empregadas foram aluminas eletrofundidas brancas (Elfusa Geral de Eletrofusão Ltda) e calcinadas (A1000 SG e A3000 FL - Alcoa EUA), microssílica (917-D - Elken), além da utilização de $2 \%$ em peso de cimento de aluminato de cálcio (CA 14 - Alcoa EUA). Os concretos foram formulados de acordo com o modelo de distribuição de tamanho de partículas de Andreasen. Foram preparadas cinco composições, variando-se o teor de microssílica de 0 a $8 \%$ (\%-p). A Tabela I exibe as principais características de cada composição, onde o IPS corresponde à distância média de separação entre as partículas da matriz [4].

Tabela I: Características das composições formuladas. [Table I: Features of the castables compositions.]

\begin{tabular}{cccc}
$\begin{array}{c}\text { Teor de } \\
\begin{array}{c}\text { Microssílica } \\
(\%-\mathrm{p})\end{array}\end{array}$ & $\begin{array}{c}\text { Coeficiente de } \\
\text { Andreasen } \\
-\mathrm{q}(-)\end{array}$ & $\begin{array}{c}\text { Matriz } \\
(\%-\mathrm{vol})\end{array}$ & IPS $(\mu \mathrm{m})$ \\
\hline 0 & 0,26 & 35,17 & 0,047 \\
\hline 2 & 0,25 & 37,37 & 0,036 \\
\hline 4 & 0,23 & 39,44 & 0,024 \\
\hline 6 & 0,21 & 41,53 & 0,016 \\
\hline 8 & 0,20 & 43,68 & 0,011 \\
\hline
\end{tabular}

Tendo em vista que a microssílica foi adicionada em função da redução proporcional das demais matérias primas constituintes do concreto, exceto o cimento, o aumento no teor desse material fez com que a proporção de matriz se elevasse, reduzindo, consequentemente, o coeficiente de empacotamento de Andreasen (Tabela I).

A mistura das matérias primas foi realizada em um reômetro para concretos [4]. O teor de água utilizado para o processamento foi de $4,51 \%$ em peso, e o aditivo dispersante foi um policarboxilato (SKW - Alemanha). Após a mistura, os concretos com diferentes teores de microssílica foram submetidos à medida de fluência livre (norma ASTM C230) e posteriormente moldados para realização dos ensaios de permeabilidade, resistência mecânica e explosão. A cura a 8 ${ }^{\circ} \mathrm{C}$ empregada em várias etapas deste trabalho permite que a resistência à explosão do concreto seja melhor avaliada, conforme [5].

\section{Medidas de permeabilidade}

Para a determinação da permeabilidade ao ar em temperatura ambiente, utilizaram-se corpos de prova cilíndricos [altura (h) de $25 \mathrm{~mm}$ e diâmetro (d) de $75 \mathrm{~mm}$ ] que foram curados à temperatura de $8^{\circ} \mathrm{C}$ (umidade relativa $\sim 100 \%$ ) por $72 \mathrm{~h}$, e secos na mesma temperatura por $96 \mathrm{~h}$ em recipiente fechado contendo sílica gel. Ambas as etapas (cura e secagem) foram realizadas em uma câmara climática (Vötsch, modelo 20-20). O ensaio de permeabilidade foi realizado em um equipamento hidrodinâmico desenvolvido em laboratório. A constante de permeabilidade não-darciana $\left(\mathrm{k}_{2}\right)$ foi obtida ajustando-se os dados a uma equação polinomial (Equação de Forcheimer) [6].

\section{Resistência mecânica}

O ensaio de resistência mecânica (compressão diametral Norma ASTM C 496-90) foi realizado em amostras cilíndricas ( $\mathrm{h}=\mathrm{d}=40 \mathrm{~mm}$ ) secas (segundo procedimentos descritos acima) e úmidas (pós cura), utilizando-se um equipamento de ensaios universal MTS 810 com taxa de aplicação de carga constante (42 N/s).

Os ensaios descritos anteriormente (resistência mecânica e permeabilidade) foram repetidos para os concretos contendo $8 \%$ em peso de microssílica, utilizando-se outras temperaturas de cura e de secagem $\left(30\right.$ e $\left.50^{\circ} \mathrm{C}\right)$. Tais ensaios também foram realizados em corpos de prova com teores de 0,4 e $8 \%$ em peso de microssílica, curados a $8^{\circ} \mathrm{C}$ por $72 \mathrm{~h}$ e secos a $110^{\circ} \mathrm{C}$ durante $5 \mathrm{~h}$.

\section{Ensaio de explosão}

Para avaliar a resistência à explosão dos concretos, foram moldadas amostras cilíndricas $(\mathrm{h}=\mathrm{d}=40 \mathrm{~mm})$ com teores de 0,4 e $8 \%$ em peso de microssílica, e curadas a $8^{\circ} \mathrm{C}$ por $72 \mathrm{~h}$ (umidade relativa $\sim 100 \%$ ).

O ensaio de explosão consistiu na introdução das amostras em uma mufla pré-aquecida na temperatura de interesse (300, 400 e $500^{\circ} \mathrm{C}$ ) e na verificação da ocorrência de explosão durante um intervalo de até 20 minutos após o início do aquecimento das mesmas. Caso não viessem a explodir durante esse intervalo de tempo, considerou-se que sobreviveram ao teste [7].

\section{RESULTADOS E DISCUSSÃO}

Às diferentes composições foi adicionado o mesmo volume de água, resultando no comportamento de fluência livre observado na Fig. 1.

Neste estudo, a quantidade de matriz foi fundamental no controle da fluidez do concreto, originando dois comportamentos distintos:

1) Com baixo teor de matriz, como no caso do concreto com $0 \%$ de microssílica, predominaram os contatos entre os agregados, o que resultou em baixa ou nenhuma fluidez. 


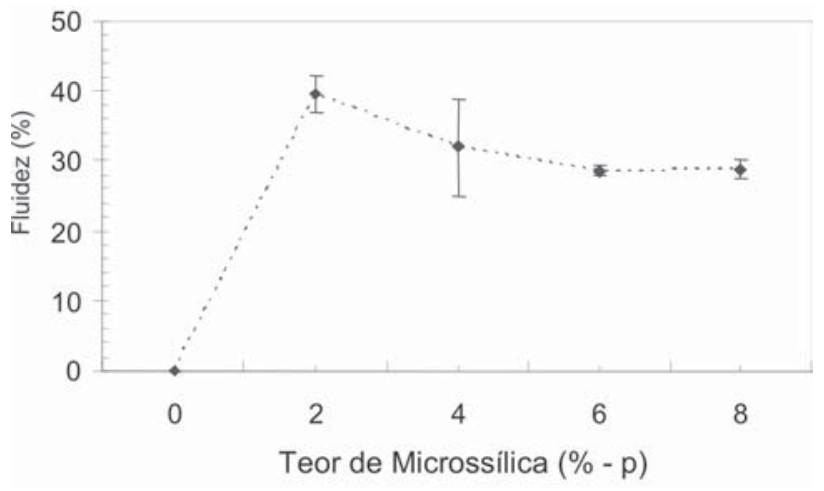

Figura 1: Fluência livre após mistura em função do teor de microssílica.

[Figure 1: Free flow after mixing as a function of the microsilica content.]

2) Com o aumento do teor de matriz presente, o valor de fluidez aumentou rapidamente, como verificado para a composição com $2 \%$ em peso de microssílica, visto que a introdução de superfinos promoveu um efeito lubrificante entre os agregados (efeito rolamento). Para adições superiores a 2\%, a fluidez passou a ser governada pela viscosidade da matriz [8].

Como o teor de água foi mantido constante e o aumento gradativo do teor de microssílica causou redução na distância de separação entre as partículas da matriz (redução de IPS Tabela I), a viscosidade local foi elevada, gerando a redução de fluidez visualizada na Fig. 1.

A influência da introdução e variação no teor de microssílica na resistência mecânica e permeabilidade, para os concretos curados a $8^{\circ} \mathrm{C}$, pode ser observada nas Figs. 2 e 3 , respectivamente.

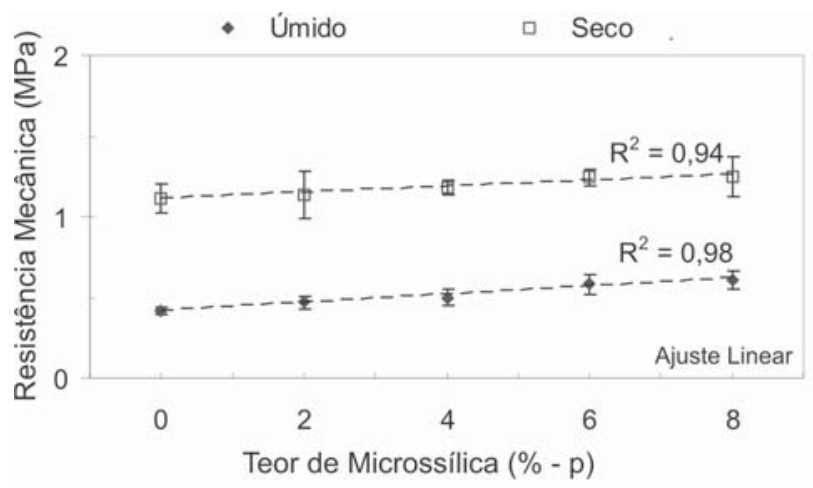

Figura 2: Resistência mecânica em função do teor de microssílica para ensaios realizados em amostras úmidas curadas a $8^{\circ} \mathrm{C}$ e secas em sílica gel na mesma temperatura.

[Figure 2: Mechanical strength as a function of microsilica content for wet samples cured at $8^{\circ} \mathrm{C}$ and dried in silica gel at the same temperature.]
Verificou-se um gradativo aumento da resistência mecânica com a elevação do teor de microssílica, tanto para amostras úmidas, quanto secas. Este efeito pode ser devido a um melhor empacotamento das partículas, produzido pelo preenchimento dos espaços disponíveis pela microssílica, embora não tenha sido detectada redução significativa na porosidade das amostras com o aumento do teor de microssílica.

Segundo a literatura, a utilização de baixas temperaturas de cura $\left(<10^{\circ} \mathrm{C}\right.$ ) age de maneira significativa no comportamento pozolânico da microssílica, reduzindo de forma eficaz sua cinética de reação [3]. Apesar desses relatos, tal reação pode ter sido iniciada, tornando-se mais efetiva com o aumento do teor de microssílica. Essa seria uma outra hipótese para o aumento de resistência mecânica verificado na Fig. 2.

A Fig. 3 ilustra o comportamento de permeabilidade dos concretos com diferentes teores de microssílica curados a 8 ${ }^{\circ} \mathrm{C}$. Nota-se que a constante de permeabilidade não-darciana $\left(\mathrm{k}_{2}\right)$ apresentou um decréscimo significativo com o aumento do teor de microssílica. Tendo em vista que a elevação na quantidade de microssílica tem como conseqüência a redução da distância média entre as partículas da matriz (diminuição de IPS - Tabela I), pode-se afirmar que após a secagem são geradas estruturas menos permeáveis em concretos com maiores teores de microssílica.

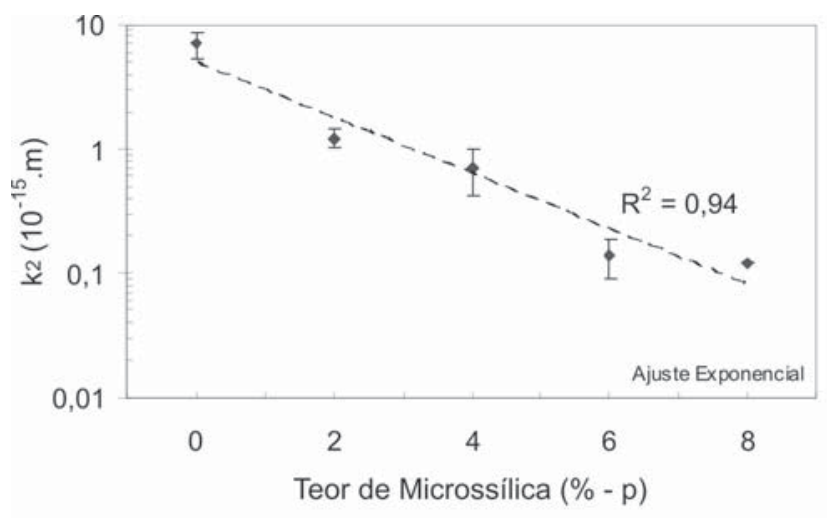

Figura 3: Constante de permeabilidade não-darciana $\left(\mathrm{k}_{2}\right)$ em função do teor de microssílica para concretos curados e secos em sílica gel a $8^{\circ} \mathrm{C}$. [Figure 3: Non-Darcian permeability constant $\left(k_{2}\right)$ as a function of microsilica content for castables cured and dried in silica gel at $8{ }^{\circ} \mathrm{C}$.]

Uma vez que a reação pozolânica pode ser acelerada com o aumento da temperatura [3], essa provavelmente contribuiu para o aumento da resistência mecânica dos concretos curados em temperaturas mais elevadas, como verificado na Fig. 4, para a composição contendo $8 \%$ em peso de microssílica, tanto para amostras úmidas quanto secas. Outro fator contribuinte é a aceleração da hidratação do cimento com a temperatura, fato que contribui para a formação de maior quantidade de fases hidratáveis e, conseqüentemente, aumento da resistência mecânica [5].

Apesar da redução da temperatura atenuar a reação do cimento, os hidratos gerados são menos densos que aqueles 


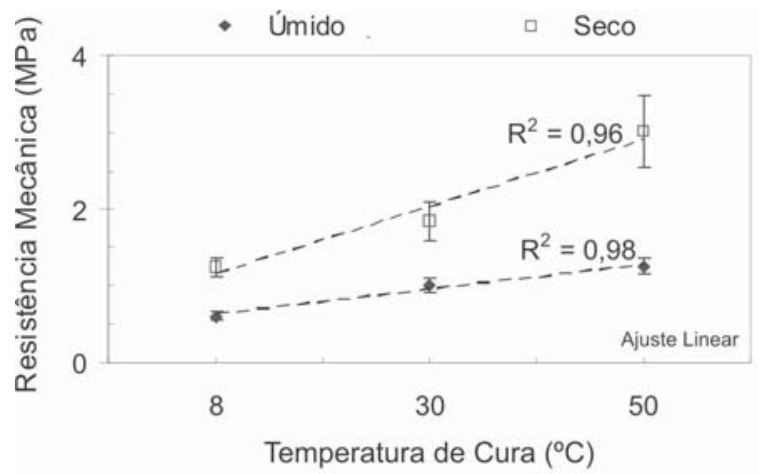

Figura 4: Resistência mecânica em função da temperatura de cura para ensaios realizados em amostras úmidas e secas em sílica gel, para corpos contendo $8 \%$ em peso de microssílica.

[Figure 4: Mechanical strength as a function of curing temperature for tests in wet samples dried in silica gel, for bodies containing $8 \%$-wt of microsilica.]

formados em alta temperatura, podendo, portanto, bloquear com maior efetividade a passagem de um fluido pela estrutura do concreto. Além disso, em baixas temperaturas de cura também é formada a alumina gel, um composto que possui elevada eficiência no preenchimento dos espaços disponíveis, gerando uma estrutura menos permeável [5]. Tais fatores provavelmente seriam a causa da elevação da permeabilidade dos concretos com o aumento da temperatura de cura (Fig. 5).

Os resultados do ensaio de explosão realizados em diferentes temperaturas, para os concretos com diversos teores de microssílica podem ser observados na Tabela II.

Para melhor compreender estes resultados, foram realizados ensaios de resistência mecânica e permeabilidade com amostras curadas a $8{ }^{\circ} \mathrm{C}$ por $72 \mathrm{~h}$, sendo secas, logo a seguir, à $110^{\circ} \mathrm{C}$ por $5 \mathrm{~h}$ (Fig. 6). Tal experimento visou simular

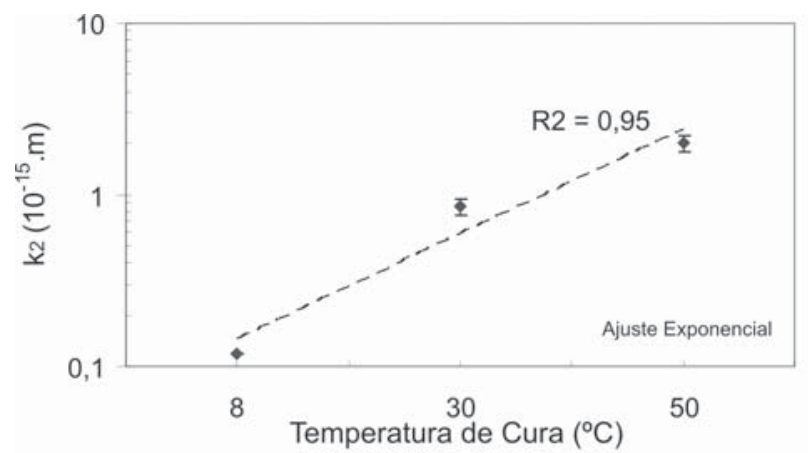

Figura 5: Constante de permeabilidade não-darciana $\left(\mathrm{k}_{2}\right)$ em função da temperatura de cura para corpos contendo $8 \%$ em peso de microssílica.

[Figure 5: Non-Darcian permeability constant $\left(k_{2}\right)$ as a function of curing temperature for castables containing $8 \%$-wt of microsilica.]
Tabela II - Tempo para explosão em função do teor de microssílica de amostras curadas a $8{ }^{\circ} \mathrm{C}$ para as temperaturas de ensaio de 300,400 e $500{ }^{\circ} \mathrm{C}$.

[Table II - Time for explosion as a function of microsilica content for the samples cured at $8^{\circ} \mathrm{C}$.Testing temperatures of 300,400 and $500{ }^{\circ} \mathrm{C}$.]

\begin{tabular}{cccc}
\hline $\begin{array}{c}\text { Teor de } \\
\text { Microssílica } \\
(\%-\mathrm{p})\end{array}$ & \multicolumn{3}{c}{$\begin{array}{c}\text { Tempo para explosão (min) } \\
\text { em função da temperatura }\end{array}$} \\
\hline \multicolumn{4}{c}{ de ensaio. } \\
\hline 0 & Não explodiu & $800^{\circ} \mathrm{C}$ & $500^{\circ} \mathrm{C}$ \\
\hline 4 & Não explodiu & Não explodiu & Não explodiu \\
\hline 8 & Não explodiu & Não explodiu & $6,95^{*}$ \\
\hline
\end{tabular}

* Somente $40 \%$ das amostras explodiram

uma condição de secagem mais próxima da ocorrida nos ensaios de explosão e avaliar a contribuição das fases formadas na presença de alguma reação que afetasse essa variável durante a secagem.

Os resultados confirmaram que com o aumento do teor de microssílica, houve um aumento da resistência mecânica à medida que o concreto, mesmo curado a $8{ }^{\circ} \mathrm{C}$, é aquecido e
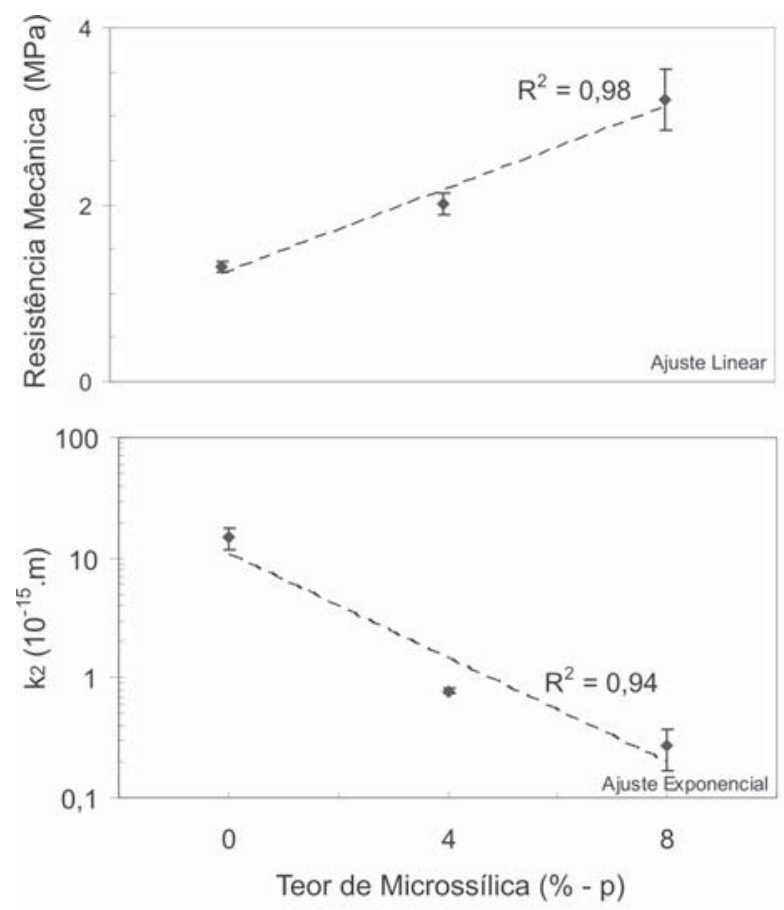

Figura 6: Resistência mecânica (a) e constante de permeabilidade não-darciana $\left(\mathrm{k}_{2}\right)(\mathrm{b})$ em função do teor de microssílica para ensaios realizados em amostras curadas a $8{ }^{\circ} \mathrm{C}$ e secas a $110{ }^{\circ} \mathrm{C}$.

[Figure 6: Mechanical strength (a) and non-Darcian permeability constant $\left(k_{2}\right)(b)$ as a function of microsilica content for tests in samples cured at $8{ }^{\circ} \mathrm{C}$ and dried at $110^{\circ} \mathrm{C}$.] 
passa pelo processo parcial de secagem. Por outro lado, a permeabilidade se comportou de maneira inversa, ou seja, ocorreu redução dessa propriedade com o aumento no teor de microssílica.

A partir dessas observações, foi possível interpretar com maior segurança os resultados da Tabela II. Sabe-se que a resistência à explosão de um corpo cerâmico depende basicamente de um balanço entre sua resistência mecânica e a permeabilidade. A partir do momento que a formação de vapor supera a sua taxa de liberação, a pressão no interior do corpo cerâmico se eleva, causando possivelmente a explosão. Por outro lado, o aumento de resistência mecânica também contribui para o aumento da resistência à explosão, uma vez que o corpo cerâmico pode suportar um maior nível de pressurização.

Em relação aos resultados obtidos, nota-se na Tabela II que a $300{ }^{\circ} \mathrm{C}$ nenhuma amostra explodiu, pois o efeito da resistência mecânica superou o efeito da permeabilidade, ou seja, o vapor d'água pôde ser eliminado com certa facilidade, não promovendo elevação da pressão acima dos níveis de resistência mecânica.

Nos testes efetuados à $400^{\circ} \mathrm{C}$, apenas os corpos isentos de microssílica sofreram explosão. Nota-se que a permeabilidade nos corpos sem microssílica apresenta valores superiores aos demais, reduzindo provavelmente a pressão gerada pelo vapor d'água. Apesar disso, tais corpos apresentaram menor resistência mecânica, o que por si só resultaria em menor resistência à explosão.

A $500{ }^{\circ} \mathrm{C}$, as amostras sem microssílica explodiram em um tempo menor do que as ensaiadas à $400^{\circ} \mathrm{C}$, devido provavelmente a sua menor resistência mecânica. Os corpos de prova com $4 \%$ em peso de microssílica continuaram resistentes à explosão, demonstrando possivelmente que nestas amostras obteve-se um balanço ideal entre resistência mecânica e permeabilidade. Dentre os corpos com $8 \%$ em peso de microssílica, $40 \%$ sofreram explosão, significando que a relação permeabilidade/ resistência mecânica pode ter sido alterada com a redução da permeabilidade provocada pela adição de microssílica. Provavelmente, o aumento na temperatura de ensaio (as quais seriam responsáveis por maiores níveis de tensão gerada), ou o uso de corpos com teores mais elevados de microssílica geraria situações ainda mais favoráveis à ocorrência de explosão.

\section{CONCLUSÕES}

Existe uma quantidade ótima de microssílica, a ser adicionada em concretos refratários com ultrabaixo teor de cimento, que contribui para o aumento da resistência mecânica sem afetar consideravelmente a permeabilidade, levando a um balanço de forças que confere ao corpo uma resistência à explosão sob variações bruscas de temperatura $\left(\sim 500{ }^{\circ} \mathrm{C}\right)$. Neste trabalho, para ressaltar esse aspecto, os concretos foram curados a baixa temperatura. No entanto, os efeitos da presença da microssílica podem ser extrapolados para cura em temperaturas superiores $\left(30\right.$ ou $\left.50^{\circ} \mathrm{C}\right)$.

\section{AGRADECIMENTOS}

Os autores agradecem à Alcoa Brasil e à Elfusa Geral de Eletrofusão Ltda. pelo fornecimento das matérias-primas.

\section{REFERÊNCIAS}

[1] B. Myhre, The effect of particle-size distribution on flow of refractory castables, The American Ceramic Society $30^{\text {th }}$ Annual Refractories Symposium, St. Louis, Missouri (1994) 3-7

[2] A. Hundere, B. Myhre, On the influence of superfines in high alumina castables, XXXIX International Colloquium on Refractories, Aachen, Germany (1996) 2-7

[3] A. Neville, Concrete Technology, Longman Scientific and Technical, revised reprint (1990) Chapter 17 and 19.

[4] R. G. Pileggi, V.C. Pandolfelli,A. E. Paiva, J. Gallo, Novel rheometer for refractory castables, Am. Ceram. Soc. Bull. 79, 1 (2000) 54-58.

[5] F. A. Cardoso, M. D. M. Innocentini, M. M. Akiyoshi, V. C. Pandolfelli, Effect of Curing Conditions on the Properties of Ultra-low Cement Refractory Castables, Refractories Applications and News 9, 2 (2004) 12-16.

[6] M. D. M. Innocentini, V. C. Pandolfelli, Considerações sobre a estimativa da permeabilidade em concretos refratários através das equações de Darcy e Forchheimer, Cerâmica 45, 292-293 (1999) 61-67.

[7] A. P. M. Menegazzo, Dissertação de Mestrado, DEMaUFSCar, PPG-CEM (1996) 132p.

[8] I. R. Oliveira, A. R. Studart, R. G. Pileggi, V. C. Pandolfelli, Dispersão e empacotamento de partículas - princípios básicos e aplicações no processamento cerâmico, Fazendo Arte Editorial (2000) 224.

(Rec. 25/05/04, Ac. 24/09/04) 